ORIGINAL ARTICLE

\title{
Risk factors for injuries in elite female soccer players
}

\author{
O Faude, A Junge, W Kindermann, J Dvorak
}

See end of article for authors' affiliations ....................

Correspondence to: O Faude, Institute of Sports and Preventive Medicine, University of Saarland, Campus Bldg B8.2, 66123 Saarbrücken, Germany; o.faude@mx.uni-saarland. de

Accepted 22 June 2006

Published Online First 6 July 2006

\begin{abstract}
Objective: To describe risk factors for injuries in elite female soccer.
Methods: A total of 143 female soccer players from the German national league participated in the study. Baseline information on player characteristics - for example, anthropometric measurements and playing position-and medical history were recorded at the start of the study. During one outdoor season, injuries and training and match exposure times were prospectively documented for each player.

Results: The risk of a new anterior cruciate ligament $(A C L)$ rupture was significantly increased in players with a previous rupture (odds ratio $(O R)=5.24, p=0.01$ ). This was not the case for ankle sprain (OR = 1.39) or knee sprain $(O R=1.50)$. In addition, no significantly increased risk of new sprains or $A C L$ ruptures was found when the injured leg was the unit of analysis. Injury incidence was considerably higher in defenders (9.4 injuries per 1000 hours exposure) and strikers (8.4/1000 hours) than goalkeepers (4.8/1000 hours) and midfielders (4.6/1000 hours). Ten per cent of all players $(n=14)$ sustained more than three injuries. Most of these were defenders $(n=8)$ or strikers $(n=4)$. Significantly more injuries occurred to the dominant leg $(105 \vee 71, p=0.01)$; this was particularly true for contact injuries (52 v 29, $\mathrm{p}=0.011$.

Conclusions: Injury risk should be assessed on an individual basis. Therefore it seems appropriate to individualise preventive training programmes, as is recommended for other training content. Evaluating the existing rules of soccer and their appropriate application may also help to decrease injury risk, particularly in contact situations.
\end{abstract}

S occer is a complex, high intensity, contact sport and therefore associated with a great injury risk. A high injury incidence may have serious consequences for the players, the clubs, and the public health systems. For instance, in the study of de Loes et al ${ }^{1}$ of 3611 subjects from different team sports, the total injury cost for 3864 knee injuries was US\$ 4268014 . The highest costs for knee injuries were in female soccer players, with an average of US\$ 1861 per injury. These data show that injuries represent a serious concern in team sports, and therefore it is necessary to introduce adequate preventive measures.

According to a classical model of injury prevention, ${ }^{23}$ the first step should be investigation of the incidence of the injury with regard to the population of interest. Thereafter, it is necessary to identify the risk factors and injury mechanisms in order to be able to introduce and establish adequate preventive intervention strategies. Finally, the intended prophylactic measures should be validated by repeating step 1 .

Epidemiological data on injuries in elite female soccer players are rare. Recently, Giza et al ${ }^{4}$ reported relatively low incidence rates during two seasons in the Women's United Soccer Association. Unfortunately, the results of this study may be biased because an insurance database was analysed. It is possible that some minor injuries were not recorded and, in consequence, the total injury incidence may have been underestimated. In contrast, a recent prospective epidemiological study arrived at the conclusion that, in high level female soccer, injury incidence is as high as in professional male soccer. ${ }^{5}$ These results are in line with earlier observations by Engstroem et al, ${ }^{6}$ who also observed high incidences in two teams from the Swedish first and second divisions. Similar rates have been reported for female players during major soccer tournaments such as World Championships and Olympic Games (on average 30 time-loss injuries per 1000 playing hours in six tournaments). ${ }^{7}$

Analyses of risk factors in elite soccer players are also scarce. Arnason $e t \mathrm{al}^{8}$ investigated male soccer players from the two highest divisions in Iceland. They found increasing age and previous injury to be the main risk factors in this population. This result was confirmed by Ostenberg and Roos, ${ }^{9}$ who studied 123 female players from eight teams of mainly subelite level. In contrast, no effect of age on injury risk was observed by Soderman et al ${ }^{10}$ analysing risk factors for leg injuries in 146 female soccer players from the Swedish second and third divisions. Although many possible variables have been evaluated in studies on risk factors, only a few consistent results have been reported. ${ }^{11}$ This may partly be due to differences in, for instance, the sex or skill level of the populations investigated. No study has so far analysed risk factors for injuries in elite female soccer players.

In this study, we aimed to identify risk factors for injuries in female soccer players in the German national league on the basis of player characteristics and prospective injury record over a whole outdoor season.

\section{METHODS}

All 12 teams of the German national women's league were asked to participate in this prospective study. After players had given their informed consent, baseline information was recorded by the teams' physiotherapists for all players. The team coaches reported training and match exposure weekly on an individual basis. Trainers were advised to document each day that a player missed or could not take part fully in training and/or a match because of an injury associated with soccer, or if she missed training or a match for some other reason (soccer unrelated injury, private reasons, infection, etc). The team physiotherapists reported all injuries. They were with their teams for most training session and during matches. All information was recorded on specially designed forms. One author (OF) regularly contacted trainers and physiotherapists by telephone or email to evaluate the exact diagnosis and ensure compliance.

The study was approved by the local ethics committee. 
Table 1 Anthropometric data and exposure of players who sustained an injury compared with uninjured players

\begin{tabular}{|c|c|c|c|c|c|c|c|}
\hline & \multicolumn{3}{|c|}{ Risk factor as continuous variable } & \multicolumn{4}{|c|}{ Risk factor as categorical variable } \\
\hline & $\begin{array}{l}\text { Injured } \\
(n=99)\end{array}$ & $\begin{array}{l}\text { Uninjured } \\
(n=44)\end{array}$ & $\mathrm{p}$ Value & $>1$ SD below mean & $p$ Value & $>1 \mathrm{SD}$ above mean & p Value \\
\hline Age (years) & $22.6(4.9)$ & $21.8(5.0)$ & 0.35 & $0.70(0.27$ to 1.81$)$ & 0.47 & $1.21(0.41$ to 3.49$)$ & 0.74 \\
\hline Weight $(\mathrm{kg})$ & $61.8(6.2)$ & $60.3(6.0)$ & 0.18 & $0.56(0.21$ to 1.52$)$ & 0.27 & $1.92(0.62$ to 5.84$)$ & 0.27 \\
\hline Height $(\mathrm{cm})$ & $169(6)$ & $169(5)$ & 0.51 & $1.70(0.59$ to 4.85$)$ & 0.34 & 9.64 (1.56 to 58.52$)$ & 0.01 \\
\hline $\mathrm{BMI}\left(\mathrm{kg} / \mathrm{m}^{2}\right)$ & $21.5(1.3)$ & $21.2(1.5)$ & 0.18 & $0.58(0.22$ to 1.54$)$ & 0.29 & $0.68(0.26$ to 1.76$)$ & 0.44 \\
\hline Games last season & $24(11)$ & $25(12)$ & 0.62 & $1.49(0.51$ to 4.26$)$ & 0.48 & $0.81(0.30$ to 2.19$)$ & 0.69 \\
\hline Training time (hours) & $175(73)$ & $202(65)$ & 0.04 & $3.15(0.91$ to 10.7$)$ & 0.07 & $1.17(0.48$ to 2.80$)$ & 0.74 \\
\hline Match time (hours) & 29 (14) & $33(16)$ & 0.13 & $0.93(0.36$ to 2.42$)$ & 0.89 & $0.26(0.10$ to 0.67$)$ & 0.004 \\
\hline Exposure time (hours) & $204(78)$ & $235(71)$ & 0.03 & $3.17(0.92$ to 10.73$)$ & 0.07 & $0.90(0.38$ to 2.15$)$ & 0.82 \\
\hline Training to match ratio* & $5.5(3.9-8.0)$ & $6.0(4.0-9.8)$ & 0.49 & & & & \\
\hline
\end{tabular}

Values are mean (SD) or odds ratio (95\% confidence interval). The odds ratios (95\% confidence intervals) were calculated for the players 1 SD below and above the mean respectively compared with the intermediate group as reference group.

*Because training exposure was very high in relation to match exposure in some players, training to match ratio was not normally distributed, and therefore median and upper and lower quartiles are given. Statistical comparison between the injured and the uninjured group was performed by the Mann-Whitney $U$ test. For the same reason, it was not possible to analyse training to match ratio as a categorical risk factor.

$\mathrm{BMI}$, Body mass index.

\section{Subjects}

Eight teams provided baseline information as well as complete data on injuries and exposure times. This corresponds to 143 players (22.4 (5.0) years of age; 61 (60) kg; 169 (6) $\mathrm{cm}$; mean (SD)) from the German national league. They were followed over a whole outdoor season from August 2003 to mid-June 2004, including preseason conditioning.

\section{Baseline information}

Baseline information was recorded at the start of the season for each player by the physiotherapist. Anthropometric data as well as information on playing position, dominant leg, and the number of games played during the previous season were reported. Medical history, particularly on previous ligament injuries, was also collected.

\section{Injury definition and injury recording}

According to the definition of the National Athletic Injury Registration System of the United States, any physical complaint associated with soccer (received during training or match play), which limits athletic participation for at least the day after the day of onset, was defined as a soccer injury. ${ }^{2}$ A player was deemed injured until she was able to participate fully again in games and/or training.

An injury was classified as an overuse injury if it was the consequence of repetitive microtraumas, and as traumatic if it was caused by a single traumatic incident. ${ }^{2}$ Traumatic injuries were classified as contact or non-contact.

Information on location, type, exact diagnosis, and the occasion and mechanism were recorded in an injury recording protocol by the physiotherapists.

A sprain was defined as an acute distraction injury of a ligament or joint capsule. Because there are considerable differences in the consequences of grade I and grade III (complete rupture of ligament) sprains, ${ }^{13}$ some results are also given for ligament ruptures only.

\section{Statistical analysis}

Continuous data were reported as mean (SD), and frequency tables were used for categorical data. $t$ Tests for independent variables were used to compare injured and uninjured players, when risk factors were treated as continuous variables. For the categorical analysis, players were classified into three groups. Odds ratios (ORs) and 95\% confidence intervals $(95 \% \mathrm{CI})$ were computed for the players with the lowest $(>1$ SD below the mean) and highest $(>1$ SD above the mean) values for each variable compared with the intermediate group as reference group. ${ }^{8}{ }^{13}$ Differences in the incidence of injuries to the dominant and non-dominant leg were calculated using the $\chi^{2}$ test. ORs $(95 \% \mathrm{CI})$ were determined to compare the risk of sustaining a new ligament injury with a history of the same injury. p Values for ORs were obtained by the Mantel-Haenszel test. 95\%CI for injury rates at the different playing positions were calculated according to the following formula:

$95 \% \mathrm{CI}=$ incidence $\pm 1.96 \times($ incidence $/ \sqrt{ }($ number of incidents)).

Significance was accepted at $\mathrm{p}<0.05$.

\section{RESULTS}

A detailed description of the epidemiology of the injuries in this study population has been published. ${ }^{5}$

\section{Anthropometric characteristics and exposure data} The tallest players $(>1$ SD above the mean-that is, taller than $175 \mathrm{~cm}$ ) showed a significantly increased injury risk compared with those of intermediate height (table 1). Players who sustained a non-contact injury had a significantly higher body weight and had played significantly more games during the previous season (table 2).

The injured players, particularly those with a non-contact injury, had a significantly reduced training and total exposure time (tables 1 and 2). The players with the highest match exposure ( $>1$ SD above the mean-that is, more than 45 hours per season) had a significantly reduced injury risk compared with the reference group (table 1).

\section{Previous ligament injuries}

The risk of sustaining an anterior cruciate ligament (ACL) rupture was significantly increased in players who had reported a previous one (fig 1). Players with previous sprains of the ankle and knee had a slightly, but not significantly, higher risk of the same injury. When each leg was treated as a separate case, no higher risk of an actual sprain in players with a previous sprain was found. OR (95\%CI) was $0.71(0.31$ to $1.62 ; \mathrm{p}=0.42$ ) for ankle sprains, 0.99 (0.39 to $2.54 ; \mathrm{p}=$ $0.98)$ for knee sprains, and 1.71 (0.38 to $7.84 ; \mathrm{p}=0.52)$ for ACL ruptures.

\section{Playing position}

Defenders and strikers showed a considerably higher incidence than goalkeepers and midfielders (fig 2). Goalkeepers' injuries were mostly due to non-contact mechanisms (15 of 20 injuries), whereas defenders and strikers were at increased risk in contact situations (4.5 injuries per 1000 hours exposure each). 
Table 2 Anthropometric data and exposure of players who sustained an injury compared with uninjured players, with injuries separated into overuse, contact, and non-contact

\begin{tabular}{|c|c|c|c|c|c|c|c|c|c|}
\hline & \multicolumn{3}{|l|}{ Overuse } & \multicolumn{3}{|l|}{ Contact } & \multicolumn{3}{|l|}{ Non-contact } \\
\hline & $\begin{array}{l}\text { Injured } \\
(n=22)\end{array}$ & $\begin{array}{l}\text { Uninjured } \\
(n=121)\end{array}$ & p Value & $\begin{array}{l}\text { Injured } \\
(n=63)\end{array}$ & $\begin{array}{l}\text { Uninjured } \\
(\mathrm{n}=80)\end{array}$ & p Value & $\begin{array}{l}\text { Injured } \\
(n=56)\end{array}$ & $\begin{array}{l}\text { Uninjured } \\
(n=87)\end{array}$ & p Value \\
\hline Age (years) & $22.6(4.5)$ & $22.3(5.1)$ & 0.77 & $23.2(5.4)$ & $21.7(4.5)$ & 0.08 & $21.9(4.0)$ & $22.7(5.5)$ & 0.35 \\
\hline Weight $(\mathrm{kg})$ & $62.4(5.4)$ & $61.2(6.3)$ & 0.38 & $61.1(5.6)$ & $61.5(6.6)$ & 0.71 & $62.6(6.7)$ & $60.5(5.6)$ & 0.05 \\
\hline Height $(\mathrm{cm})$ & $170(6)$ & $169(6)$ & 0.56 & $169(6)$ & $169(5)$ & 0.98 & $170(6)$ & $169(5)$ & 0.17 \\
\hline BMI $\left(\mathrm{kg} / \mathrm{m}^{2}\right)$ & $21.6(1.2)$ & $21.3(1.4)$ & 0.41 & $21.3(1.2)$ & $21.4(1.5)$ & 0.64 & $21.6(1.3)$ & $21.2(1.4)$ & 0.13 \\
\hline Games last season & $24(11)$ & $22(11)$ & 0.42 & $23(10)$ & $25(12)$ & 0.36 & $27(12)$ & $22(10)$ & 0.02 \\
\hline Training time (hours) & $173(84)$ & $185(69)$ & 0.45 & $187(72)$ & $181(72)$ & 0.61 & $164(72)$ & $196(69)$ & 0.01 \\
\hline Match time (hours) & $29(14)$ & 31 (15) & 0.67 & $31(14)$ & $30(15)$ & 0.77 & $30(15)$ & $31(15)$ & 0.60 \\
\hline Exposure time (hours) & $202(88)$ & $216(75)$ & 0.43 & $218(75)$ & $211(79)$ & 0.59 & $194(79)$ & $226(73)$ & 0.01 \\
\hline Training/match ratio* & $4.7(3.8-9.3)$ & $5.8(4.0-8.3)$ & 0.44 & $5.5(4.3-7.3)$ & $6.0(3.9-9.0)$ & 0.79 & $5.0(3.8-7.8)$ & 6.1 (4.3-9.7) & 0.13 \\
\hline
\end{tabular}

Values are mean (SD). Significant $p$ values are in bold.

*Because training exposure was very high in relation to match exposure in some players, training to match ratio was not normally distributed, and therefore median and upper and lower quartiles are given. Statistical comparison between the injured and uninjured groups was performed by the Mann-Whitney $U$ test. BMI, Body mass index.

Most $(62 \%)$ players sustained either no $(n=41)$ or only one injury $(\mathrm{n}=48)$. Twenty one players $(15 \%)$ sustained two, and 18 players (13\%) three injuries during the season. Fourteen (10\%) subjects suffered four or more injuries during the season. This $10 \%$ of players sustained 65 of 216 injuries $(30 \%)$. Noticeably, most of these subjects were defenders (n $=8)$ or strikers $(\mathrm{n}=4)$.

\section{Limb dominance}

Significantly more injuries occurred to the dominant leg (table 3); this is particularly true for overuse and contact injuries. Ankle injuries were observed significantly more often on the dominant leg. In addition, more ligament ruptures and contusions occurred on the dominant side.

\section{DISCUSSION}

The previously published epidemiology of injuries in this population revealed a high injury incidence in match play. ${ }^{5}$ Ligament injuries represent a serious concern, particularly the high number of ACL ruptures (11 ACL ruptures in match play-that is, 2.2 ACL ruptures per 1000 match hours). ${ }^{5}$ The present analyses aimed to evaluate risk factors for injuries in elite female soccer players. Whereas previous sprains at the knee or ankle did not significantly increase the risk of a new sprain, players with a previous ACL rupture were significantly more likely to sustain a second one. In addition, these results point to the importance of identifying injury prone playersthat is, to assess injury risk on an individual basis-and probably introduce position specific preventive measures.

\section{Anthropometric measures and exposure data}

Body dimensions such as height, weight, body fat content, and body mass index have previously been evaluated in various risk factor studies in soccer players. ${ }^{8}{ }^{914}$ The present results show that the tallest players are at increased risk of injury. In addition, a high body mass index may augment the risk of sustaining a non-contact injury. It could be hypothesised that an increase in body mass index and height may increase the forces on ligamentous and muscular structures during soccer play. Neuromuscular control to stabilise the joints may be more important when levers are longer or the levers are subjected to greater forces. Therefore

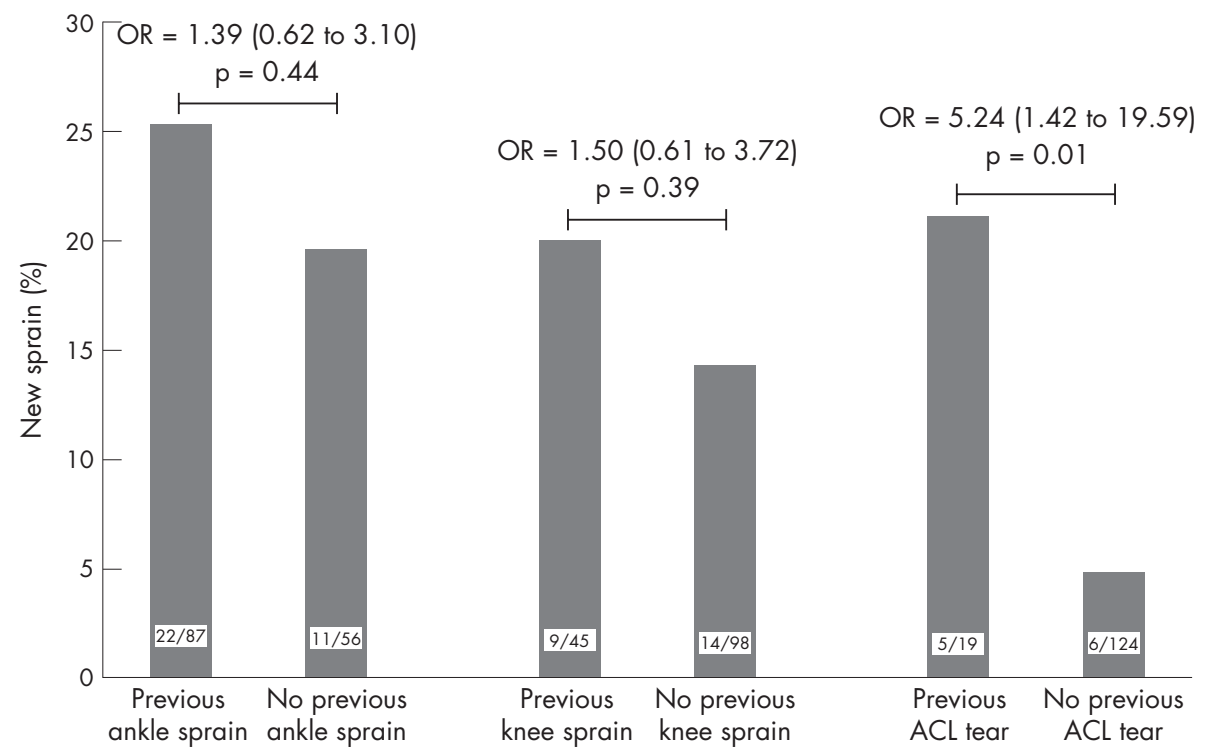

Figure 1 Risk of a new ankle sprain (left), knee sprain (middle), and anterior cruciate ligament (ACL) rupture (right) in players who had previously sustained the same injury compared with players without such a previous injury. Odds ratios (ORs) are presented with $95 \%$ confidence intervals in parentheses. 


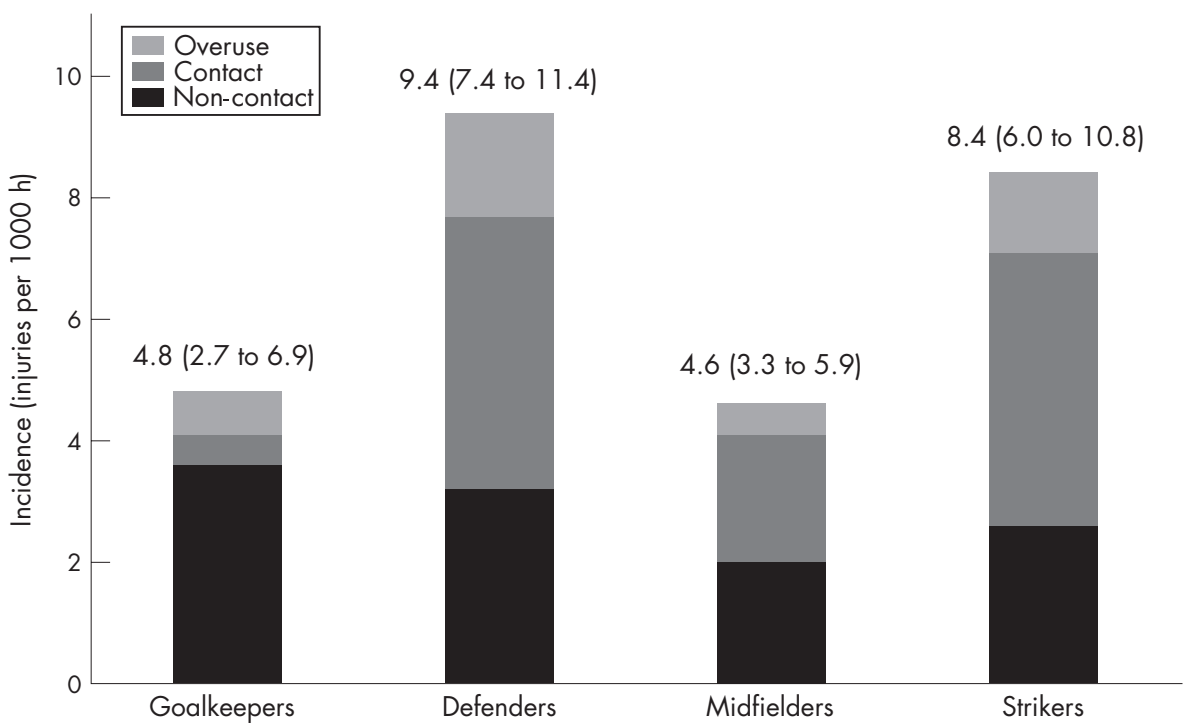

Figure 2 Incidence of injuries (and 95\% confidence intervals) for the different playing positions.

an increase in body dimensions may increase the risk of injury. ${ }^{11}$ However, most previous studies found no effect of body dimensions on injury risk. ${ }^{8}{ }^{11}$

Dvorak et $a l^{15}$ reported that low training volume may be a risk factor. High match exposure may also increase injury risk. ${ }^{8}$ Conversely, a high training to match ratio has been found to be accompanied by a reduced injury rate. ${ }^{8}{ }^{14}$ Our results show a significantly reduced training and total exposure time of the injured players as well as a lower injury risk for the players with the highest match exposure. This may be due to the time of absence resulting from injury. Therefore the lower exposure time of the injured players is probably not the cause, but rather the effect of injury. For instance, the average time of absence per injured player was 32 days-that is, $12 \%$ of the season. If this is added to the exposure time of injured players, there are no longer any differences between injured and uninjured players.

\section{Previous ligament injuries}

According to Dvorak and Junge, ${ }^{15}$ previous injuries and inadequate rehabilitation were the most important and well established risk factors for injury. This seems to be particularly true for ankle sprains. ${ }^{816-18}$ It has been hypothesised that this may be due to mechanical (persistent ligamentous laxity) or functional (proprioceptive defects) instability of the ankle after an initial sprain. ${ }^{11}{ }^{15}{ }^{19}$ In contrast with these studies, which were all conducted on male populations, the present results do not point to a significantly increased risk of ligament injuries in elite female soccer players with a history of sprains. However, we did not document the use of taping or bracing, which have been shown to prevent recurrent sprains in male athletes.

The effect of sex on the incidence of knee injury is well established, ${ }^{11} 20$ whereas the relation between sex and ankle sprains is unclear. ${ }^{112122}$ Two recently published papers by Willems et $a^{23}{ }^{24}$ point to different intrinsic risk factors for inversion ankle sprains between the sexes. Soderman et $a l^{10}$ and Ostenberg and $\operatorname{Roos}^{9}$ consistently observed general joint laxity as a risk factor in female soccer players. Although results in the literature are conflicting, there is evidence that general joint laxity may increase the risk of ankle sprain. ${ }^{21}$ In addition, a higher proportion of sprains was reported in elite

\begin{tabular}{|c|c|c|c|c|c|}
\hline & Total & Dominant & Non-dominant & $\chi^{2}$ & p Value \\
\hline \multicolumn{6}{|l|}{ Mechanism } \\
\hline Overuse & 22 & 16 & 6 & 4.545 & 0.03 \\
\hline Contact & 81 & 52 & 29 & 6.747 & 0.01 \\
\hline Non-contact & 73 & 37 & 36 & 0.014 & 0.91 \\
\hline \multicolumn{6}{|l|}{ Body part } \\
\hline Thigh, groin, hip & 56 & 33 & 23 & 1.786 & 0.18 \\
\hline Knee & 42 & 25 & 17 & 1.524 & 0.22 \\
\hline Lower leg & 19 & 7 & 12 & 1.316 & 0.25 \\
\hline Ankle & 41 & 27 & 14 & 4.122 & 0.04 \\
\hline Foot, toe & 18 & 13 & 5 & 3.556 & 0.06 \\
\hline \multicolumn{6}{|l|}{ Diagnosis } \\
\hline Sprain & 66 & 33 & 33 & 0.000 & 1.00 \\
\hline Including rupture of ligament* & 26 & 18 & 8 & 3.846 & 0.049 \\
\hline Contusion & 36 & 24 & 12 & 4.000 & 0.046 \\
\hline Strain & 33 & 19 & 14 & 0.758 & 0.38 \\
\hline Fracture & 2 & 1 & 1 & 0.000 & 1.00 \\
\hline Others & 39 & 28 & 11 & 7.410 & 0.01 \\
\hline Total & 176 & 105 & 71 & 6.568 & 0.01 \\
\hline
\end{tabular}

Significant $p$ values are in bold.

*This row shows only the number of complete ligament ruptures (grade III sprains), which are also included in the row above (all sprains grade I-III). Data in this row are not included in the totals at the bottom. 


\section{What is already known on this topic}

- There are distinct differences in the epidemiology of injuries and their risk factors between male and female players and between skill levels

- Results on injury risk factors are far from conclusive, and no studies on injury risk factors in elite female soccer players have been published

female players than has been observed in comparable male populations. This was true during whole outdoor seasons (29\% of all injuries were sprains in elite female players ${ }^{5}$ compared with, on average, $17 \%$ in top level male players $^{825}$ 26) as well as during major tournaments (25\% of all injuries were sprains in women (unpublished work) compared with $10 \%$ in elite male soccer players ${ }^{7}$ ). Hence, the present results may be explained by a greater susceptibility of female soccer players, in general, to ligament injuries, and therefore the influence of previous sprains on injury risk will be reduced.

The players who had sustained a previous ACL rupture showed a significantly increased risk of a recurrent injury when this was analysed for individual players. When each leg was treated as a separate case, ${ }^{813}$ no such effect could be found. Therefore it seems that the factors that contribute to an increased risk of recurrent ACL injuries are not related to the injured limb but to the person as a whole. ${ }^{13}$ Although no detailed data were obtained in this study, one might speculate that players who are prone to ACL ruptures may have an unusual predisposing profile of risk factors-for example, anatomical and neuromuscular characteristics, low core stability, extraordinary quadriceps dominance, aggressive playing style. Scientifically validated training programmes that reduce ACL injury rates ${ }^{27} 28$ should be regularly included in training routines, particularly for players with a history of ACL tears.

\section{Playing position}

Our results point to differences in incidence and mechanisms of injuries between playing positions. Strikers and defenders were more likely to be injured than goalkeepers and midfielders. In addition, most players with more than three injuries throughout the season were defenders or strikers. This may be explained by the finding of Rahnama et al ${ }^{29}$ that injury risk is greatest in the areas of the pitch where ball possession is most fiercely contested-that is, in the defending and attacking zones. This is supported by the finding that the risk of contact injury is increased in these playing positions. Other studies of injury risk at different playing positions have arrived at conflicting results. ${ }^{16}{ }^{17}$ 30-32 Andersen et $a^{32}$ explained these conflicting results by different playing styles between countries and levels of play. This may also explain our results, as the other investigations were carried out with male players. The present results point to the introduction of position specific preventive measures in female soccer players. For instance, evaluation as well as the consequent application of the rules of soccer, particularly with regard to player to player contact situations, as recommended for male soccer players in recent studies, ${ }^{14}{ }^{33-35}$ may protect players when challenging for the ball. Improving anticipation and awareness of the surroundings may also help to reduce in injuries in hard fought contact situations.

\section{Limb dominance}

Contact and overuse injuries predominantly occurred to the dominant leg. This is particularly true for ankle injuries. This

\section{What this study adds}

- This first study on injury risk factors in elite female soccer shows that injury history and playing position may be important

- Individual assessment of injury risk seems to be advisable, and evaluation of the application of the rules of soccer may help to decrease injury risk

finding is in line with other studies, which found more ankle sprains on the dominant leg. ${ }^{17}{ }^{24}$ Andersen et $a l^{36}$ analysed video recordings of 26 ankle injuries. They found that $88 \%$ of the identified ankle injuries were due to contact with an opponent. A lateral blow to the medial side of the lower leg was found to be the typical injury mechanism. It may be speculated that the main point of attack on the player who is in possession of the ball is the leg with which he/she kicks the ball. This is obviously the dominant side. This may also explain the high proportion of contusions on the dominant leg. Video analysis is an appropriate method for evaluating injury mechanisms in contact sports. ${ }^{33} 3637$ So far, few researchers have used this approach in soccer, ${ }^{33} 3638$ and only one study has analysed injuries in female soccer (unpublished work). There are probably differences in injury mechanisms between the sexes, and therefore video analysis of injuries in women should be extended in future research.

\section{Limitations of the study}

The number of subjects investigated and the observation period were relatively small. Following a larger group for a longer period of time may have produced more powerful results. However, this is the first study on injury risk factors in elite female soccer players, and in an elite population it is very difficult to obtain large sample sizes or to implement an ongoing surveillance system. Furthermore, the sample size in the present study is comparable to those of other risk factor studies in subelite and adolescent female players. ${ }^{10}$ In addition, the number of incidents, particularly for the calculation of the effect of previous sprains on the occurrence of new ones, is very small. However, it is comparable to the number of incidents used by Arnason et $a l^{8}$ for similar calculations for strains and sprains. For this reason, the present results should at least be seen as useful preliminary information on risk factors in elite female soccer. Future research on injury risk factors in elite female soccer players is needed to obtain more powerful results.

Some of the risk factors analysed-for example, playing position and injury history-cannot be modified to influence injury risk directly. However, awareness of these factors may help to identify players at increased risk of injury.

\section{CONCLUSION}

In summary, the results of this study suggest that it is advisable to identify injury prone players-for instance, with regard to anthropometric characteristics, playing position, and injury history. Therefore it may be appropriate to individualise training programmes for injury prevention as is already recommended for other training contents-for example, conditioning training. ${ }^{39}$ In addition, the rules of soccer and their appropriate application, particularly in contact situations, should be considered by the responsible soccer federations. Appropriate education of referees in the awarding of more stringent penalties for foul play may also help to decrease injury risk. 


\section{ACKNOWLEDGEMENTS}

We greatly appreciate the valuable support of the Federation International de Football Association (FIFA). In addition, we gratefully acknowledge the help of Hannelore Ratzeburg and Pia Hess of the German Football Association (Deutscher Fussball-Bund, DFB) for their support in coordinating the study and motivating the clubs. We also thank the trainers, physiotherapists, and players of the participating teams for their contribution to the success of this study.

\section{Authors' affiliations}

O Faude, W Kindermann, Institute of Sports and Preventive Medicine, Faculty of Clinical Medicine, University of Saarland, Saarbrücken,

Germany

A Junge, J Dvorak, FIFA-Medical Assessment and Research Centre (FMARC), Schulthess Clinic, Zurich, Switzerland

Competing interests: none declared

\section{REFERENCES}

1 de Loes M, Dahlstedt $U$, Thomee R. A 7-year study on risks and costs of knee injuries in male and female youth participants in 12 sports. Scand J Med Sci Sports 2000;10:90-7.

2 van Mechelen W, Hlobil H, Kemper HC. Incidence, severity, aetiology and prevention of sports injuries. A review of concepts. Sports Med 1992; 14:82-99.

3 Bahr R, Krosshaug T. Understanding injury mechanisms: a key component of preventing injuries in sport. Br J Sports Med 2005;39:324-9.

4 Giza E, Mithofer K, Farrell L, et al. Injuries in women's professional soccer. Br J Sports Med 2005;39:212-16.

5 Faude O, Junge A, Kindermann W, et al. Injuries in female soccer players: a prospective study in the German national league. Am J Sports Med 2005:33:1694-700.

6 Engstrom B, Johansson C, Tornkvist $\mathrm{H}$. Soccer injuries among elite female players. Am J Sports Med 1991;19:372-5.

7 Junge A, Dvorak J, Graf-Baumann T, et al. Football injuries during FIFA tournaments and the Olympic Games, 1998-2001: development and implementation of an injury-reporting system. Am J Sports Med 2004;32(suppl 1):S80-9.

8 Arnason A, Sigurdsson SB, Gudmundsson A, et al. Risk factors for injuries in football. Am J Sports Med 2004:32(suppl 1):S5-16.

9 Ostenberg A, Roos H. Injury risk factors in female European football. A prospective study of 123 players during one season. Scand J Med Sci Sports 2000; 10:279-85.

10 Soderman K, Alfredson $\mathrm{H}$, Pietila T, et al. Risk factors for leg injuries in female soccer players: a prospective investigation during one out-door season. Knee Surg Sports Traumatol Arthrosc 2001;9:313-21.

11 Murphy DF, Connolly DA, Beynnon BD. Risk factors for lower extremity injury: a review of the literature. Br J Sports Med 2003;37:13-29.

12 Faude $\mathbf{O}$, Junge $A$, Kindermann W, et al. Ligament injuries in elite female soccer players. Br J Sports Med 2005;39:383.

13 Bahr R, Holme I. Risk factors for sports injuries: a methodological approach. Br J Sports Med 2003;37:384-92.

14 Dvorak J, Junge A, Chomiak J, et al. Risk factor analysis for injuries in football players. Possibilities for a prevention program. Am J Sports Med 2000;28(suppl 5):S69-74.

15 Dvorak J, Junge A. Football injuries and physical symptoms. A review of the literature. Am J Sports Med 2000;28(suppl 5):S3-9.
16 Chomiak J, Junge A, Peterson L, et al. Severe injuries in football players. Influencing factors. Am J Sports Med 2000;28(suppl 5):S58-68.

17 Ekstrand J, Gillquist J. Soccer injuries and their mechanisms: a prospective study. Med Sci Sports Exerc 1983;15:267-70.

18 Ekstrand J, Gillquist J. The avoidability of soccer injuries. Int J Sports Med 1983;4:124-8.

19 Inklaar H. Soccer injuries. II: aetiology and prevention, Sports Med 1994;18:81-93.

20 Hutchinson MR, Ireland ML. Knee injuries in female athletes. Sports Med 1995; 19:288-302.

21 Beynnon BD, Murphy DF, Alosa DM. Predictive factors for lateral ankle sprains: a literature review. J Athl Train 2002;37:376-80.

22 Beynnon BD, Vacek PM, Murphy D, et al. First-time inversion ankle ligament trauma: the effects of sex, level of competition, and sport on the incidence of injury. Am J Sports Med 2005;33:1485-91.

23 Willems TM, Witvrouw E, Delbaere K, et al. Intrinsic risk factors for inversion ankle sprains in male subjects: a prospective study. Am J Sports Med 2005;33:415-23.

24 Willems TM, Witvrouw E, Delbaere K, et al. Intrinsic risk factors for inversion ankle sprains in females: a prospective study. Scand J Med Sci Sports 2005; 15:336-45.

25 Hawkins RD, Fuller CW. A prospective epidemiological study of injuries in four English professional football clubs. Br J Sports Med 1999:33:196-203.

26 Hagglund M, Walden M, Ekstrand J. Exposure and injury risk in Swedish elite football: a comparison between seasons 1982 and 2001. Scand J Med Sci Sports 2003; 13:364-70.

27 Heweft TE, Lindenfeld TN, Riccobene JV, et al. The effect of neuromuscular training on the incidence of knee injury in female athletes. A prospective study. Am J Sports Med 1999;27:699-706

28 Mandelbaum BR, Silvers HJ, Watanabe DS, et al. Effectiveness of a neuromuscular and proprioceptive training program in preventing anterior cruciate ligament injuries in female athletes: 2-year follow-up. Am J Sports Med 2005;33:1003-10.

29 Rahnama N, Reilly T, Lees A. Injury risk associated with playing actions during competitive soccer. Br J Sports Med 2002;36:354-9.

30 Hawkins RD, Fuller CW. An examination of the frequency and severity of injuries and incidents at three levels of professional football. Br J Sports Med 1998;32:326-32.

31 Arnason A, Tenga A, Engebretsen L, et al. A prospective video-based analysis of injury situations in elite male football: football incident analysis. Am J Sports Med 2004;32:1459-65.

32 Andersen TE, Tenga A, Engebretsen L, et al. Video analysis of injuries and incidents in Norwegian professional football. Br J Sports Med 2004;38:626-31

33 Fuller CW, Smith GL, Junge A, et al. The influence of tackle parameters on the propensity for injury in international football. Am J Sports Med 2004;32(suppl 1):S43-53.

34 Fuller CW, Junge A, Dvorak J. An assessment of football referees' decisions in incidents leading to player injuries. Am J Sports Med 2004;32(suppl 1):S17-22.

35 Andersen TE, Engebretsen L, Bahr R. Rule violations as a cause of injuries in male norwegian professional football: are the referees doing their job? Am J Sports Med 2004;32(suppl 1):S62-8.

36 Andersen TE, Floerenes TW, Arnason A, et al. Video analysis of the mechanisms for ankle injuries in football. Am J Sports Med 2004;32(suppl 1):S69-79.

37 Krosshaug T, Andersen TE, Olsen OE, et al. Research approaches to describe the mechanisms of injuries in sport: limitations and possibilities. Br J Sports Med 2005:39:330-9.

38 Giza E, Fuller C, Junge A, et al. Mechanisms of foot and ankle injuries in soccer. Am J Sports Med 2003;31:550-4.

39 Polman R, Walsh D, Bloomfield J, et al. Effective conditioning of female soccer players. J Sports Sci 2004;22:191-203. 